\title{
Conhecimento dos estudantes da saúde sobre suporte básico de vida na parada cardiorrespiratória
}

\author{
Knowledge of health students about basic life support at cardiorespiratory stop
}

Conocimiento de estudiantes de salud sobre soporte vital básico en parada cardiorrespiratoria

Luiz Felipe Xavier da Silva

ORCID: https://orcid.org/0000-0002-8027-5359 Universidade Federal do Rio Grande do Norte, Brasil

E-mail: felipeenffacisa@gmail.com

Luiz Alves Morais Filho

ORCID: https://orcid.org/0000-0002-8122-4705

Universidade Federal do Rio Grande do Norte, Brasil E-mail: moraisfilho2004@hotmail.com

Talita Araujo de Souza

ORCID: https://orcid.org/0000-0002-3138-6626

Universidade Federal do Rio Grande do Norte, Brasil

E-mail: talitaaraujo23@hotmail.com

Nathan Tierry Azevedo Costa de Medeiros

ORCID: https://orcid.org/0000-0002-8323-953X

Universidade Federal do Rio Grande do Norte, Brasil E-mail: Nathanenf1231@outlook.com

José Hiago Feitosa de Matos

ORCID: https://orcid.org/0000-0001-8473-7269 Universidade Regional do Cariri, Brasil

E-mail: jose.hiago3@gmail.com

Jeffeson Diego Alencar Silva

ORCID: https://orcid.org/0000-0002-1649-9104 Faculdade de Juazeiro do Norte, Brasil

E-mail: jefesondiego@ hotmail.com

Yaritsa Milena Martins Barbosa

ORCID: https://orcid.org/0000-0001-8735-161X Universidade Federal do Rio Grande do Norte, Brasil

E-mail: yaritsamilena@gmail.com

Ana Karoline de Freitas Nascimento

ORCID: https://orcid.org/0000-0001-9161-9332 Universidade Federal do Rio Grande do Norte, Brasil

E-mail: anakarolinefn28@gmail.com

Sara Rafaela Valcacio Camargo

ORCID: https://orcid.org/0000-0001-6984-3995

Universidade Federal do Rio Grande do Norte, Brasil

E-mail: saravalcacio26@gmail.com

José Nacélio da Silva Ferreira

ORCID: https://orcid.org/0000-0001-7394-2662

Centro Universitário Dr. Leão Sampaio, Brasil E-mail: nacelliosilva@gmail.com

\begin{abstract}
Resumo
Objetivo: Identificar o conhecimento dos estudantes de graduação na área da saúde sobre Suporte Básico de Vida na parada cardiorrespiratória. Metodologia: Trata-se de um estudo do tipo descritivo com abordagem quantitativa, realizado entre os meses de setembro e outubro de 2020 e contou com a participação de 194 alunos dos cursos de Enfermagem, Fisioterapia, Nutrição e Psicologia de uma universidade pública do Estado do Rio Grande do Norte. A coleta foi realizada pelo google forms por um questionário elaborado pelos autores baseado no protocolo de suporte básico de vida da American Heart Association. O estudo foi aprovado pelo comitê de ética em pesquisa, sob parecer $\mathrm{n}^{\circ}$ 4.018.759. Resultados: Com base nos 194 discentes que responderam as 8 questões específicas, obteve-se um total de $1.552(100 \%)$ respostas, sendo $475(30,6 \%)$ corretas, $434(27,9 \%)$ erradas e $643(41,4)$ não soube responder. Conclusão: Os achados evidenciaram um déficit no conhecimento dos alunos da área da saúde sobre o suporte básico de vida, identificando a necessidade de atividades na graduação que abordem esta temática.
\end{abstract}

Palavras-chave: Estudantes de ciências da saúde; Suporte básico de vida; Urgência e emergência; Enfermagem. 


\begin{abstract}
Objective: To identify the knowledge of undergraduate students in the health area about Basic Life Support in cardiorespiratory arrest. Methodology: This is a descriptive study with a quantitative approach, carried out between the months of September and October 2020 and with the participation of 194 students from the Nursing, Physiotherapy, Nutrition and Psychology courses of a public university in the State of Large northern river. The collection was performed by google forms through a questionnaire prepared by the authors based on the basic life support protocol of the American Heart Association. The study was approved by the research ethics committee, under opinion $\mathrm{N}^{\circ}$. 4,018,759. Results: Based on the 194 students who answered the 8 specific questions, a total of 1,552 (100\%) answers were obtained, of which $475(30.6 \%)$ were correct, $434(27.9 \%)$ were wrong and $643(41,4)$ did not know how to answer. Conclusion: The findings showed a deficit in the knowledge of students in the health area about basic life support, identifying the need for activities in undergraduate courses that address this theme.
\end{abstract}

Keywords: Health science students; Basic support of life; Urgency and emergency; Nursing.

\title{
Resumen
}

Objetivo: Identificar los conocimientos de los estudiantes de pregrado del área de la salud sobre Soporte Vital Básico en parada cardiorrespiratoria. Metodologia: Trata-se de um estudo do tipo descritivo com abordagem quantitativa, realizado entre os meses de setembro e outubro de 2020 e contou com a participação de 194 alunos dos cursos de Enfermagem, Fisioterapia, Nutrição e Psicologia de uma universidade pública do Estado do Río Grande del Norte. La recogida se realizó mediante formularios de google a través de un cuestionario elaborado por los autores en base al protocolo de soporte vital básico de la American Heart Association. El estudio fue aprobado por el comité de ética en investigación, bajo el dictamen $\mathrm{N}^{\circ}$. 4.018.759. Resultados: A partir de los 194 estudiantes que respondieron las 8 preguntas específicas, se obtuvo un total de 1.552 (100\%) respuestas, de las cuales $475(30,6 \%)$ fueron correctas, 434 $(27,9 \%)$ incorrectas y $643(41,4)$ no supo contestar. Conclusión: Los hallazgos evidenciaron un déficit en el conocimiento de los estudiantes del área de la salud sobre soporte vital básico, identificando la necesidad de actividades en los cursos de pregrado que aborden este tema.

Palabras clave: Estudiantes de ciencias de la salud; Soporte básico de vida; Urgencia y emergencia; Enfermería.

\section{Introdução}

A Parada Cardiorrespiratória (PCR) é caracterizada por um mal funcionamento cardíaco incapaz de gerar uma perfusão adequada. Esse mecanismo causa ausência de pulso ou sinais de circulação insuficiente que podem implicar em lesões irreversíveis de órgãos nobres como o cérebro, coração e pulmões, acometendo pessoas de qualquer idade e por diversos motivos em ambientes intra ou extra-hospitalares (Everett-thomas \& Ruth, 2016; Silva \& Santos, 2019; Freire \& Cavalcante, 2017; Guimaraes \& Reis, 2016).

Quando identificada, é necessário iniciar a Reanimação Cardiopulmonar (RCP) de alta qualidade, essa quando feita corretamente, conciliada ao uso do Desfibrilador Externo Automático (DEA) aumentam as chances de sobrevida em duas ou três vezes, incluindo também o cuidado em pós-PCR, deixando o índice de sobrevida em cerca de $26 \%$ e quando realizada de forma ineficaz, o índice cai para 4\%. Para o atendimento é requerido que o profissional detenha o conhecimento teórico, técnico e prático, rapidez e eficácia durante as manobras (Aha, 2019; Aha 2015; Syngletary et al., 2015; Citolino \& Nogueira, 2015).

O Suporte Básico de Vida (SBV) são os primeiros cuidados a uma pessoa com doença ou lesão aguda e tem como objetivo preservar a vida, aliviar o sofrimento, prevenir novas doenças ou lesões e a promoção da recuperação. As avaliações e intervenções devem ser clinicamente sólidas e baseadas em evidências (Aha, 2019; Citolino \& Nogueira, 2015).

Mundialmente a PCR é a principal causa de morte súbita. Segundo a Sociedade Brasileira de Cardiologia (2020), as doenças cardiovasculares, afecções do coração e da circulação, representam a principal causa de mortes no Brasil e no mundo, responsáveis por $30 \%$ dos óbitos registrados.

Considerando a importância do SBV, torna-se necessário que os alunos da área da saúde tenham conhecimento teóricoprático para realizar um atendimento precoce em situações de PCR. Para tal, as universidades devem incentivar o ensino dessa temática em disciplinas específicas da área. Os alunos tendo contato com esses assuntos irão identificar facilmente uma situação de urgência e emergência, agir rapidamente, solicitar ajuda, estando realmente preparados para atuar na área da saúde (Silva \& Santos, 2019). 
Já são vários os países europeus onde o SBV faz parte dos planos curriculares, com destaque para a Noruega, que iniciou a inclusão da formação em SBV nos currículos em 1961. É importante ressaltar a necessidade de também ensinar nas instituições de ensino superior, principalmente nos cursos da área da saúde, embora, estudos demonstram um conhecimento teórico-prático insatisfatório por parte dos profissionais e dos estudantes da área da saúde no que se refere às condutas de RCP/PCR (Aha, 2020; Tavares \& Urbano, 2016; Resende \& Carbogim, 2019) ${ }^{(12-13)}$.

Diante desse contexto, surgiu o seguinte questionamento: Qual o conhecimento dos alunos graduandos da área da saúde sobre o SBV na PCR? Assim, o objetivo do presente estudo é identificar o conhecimento de estudantes da saúde de uma universidade federal do interior do Estado do RN sobre SBV. Considerando que o presente estudo permita verificar o conhecimento dos alunos mostrando a sua importância e relevância para a formação e atuação enquanto futuros profissionais da saúde.

\section{Metodologia}

Trata-se de um estudo descritivo com abordagem quantitativa, desenvolvido em uma Universidade Pública do Rio Grande do Norte, no período do mês de Setembro e Outubro do ano de 2020.

Para Polit e Back (2018) a pesquisa quantitativa envolve a coleta sistemática de informação numérica, normalmente mediante condições de controle, além da análise dessa informação utilizando procedimentos estatísticos.

Teve como população estudantes de graduação da área da saúde. Como critérios de inclusão, alunos regularmente matriculados nos cursos de Enfermagem, Fisioterapia, Nutrição e Psicologia de todos os semestres do curso. Como critérios de exclusão: os estudantes que não preencheram o questionário no prazo estabelecido pelo pesquisador.

No período da coleta haviam 760 alunos, sendo 153 de Enfermagem, 192 de Fisioterapia, 196 de Nutrição e 219 de psicologia. Fazendo a amostra estratificada por proporção de alunos por curso, foram enviados dois e-mails com o formulário, sendo reforçado por meio de redes sociais o convite e a participação dos discentes nesta pesquisa. Inicialmente deveriam ter 57 respostas de enfermagem, 71 de fisioterapia, 73 de nutrição e 81 de psicologia. Como a coleta foi realizada por meio de um formulário eletrônico, obteve-se o número de 194 devolutivas, sendo que 50 eram discentes do curso de Enfermagem, 50 de Psicologia, 46 de Nutrição e 48 de Fisioterapia.

A coleta se deu via plataforma Google Forms ${ }^{\circledR}$, a partir de um questionário elaborado pelos autores baseado no protocolo de SBV da American Heart Association (AHA). Esse instrumento foi dividido em duas partes, na primeira foram solicitadas informações sociodemográficas quanto ao sexo, idade, formação, curso e semestre. A segunda parte são questões relacionadas com o domínio específico sobre a temática.

Os dados foram categorizados e processados eletronicamente, através dos softwares Microsoft-Excel XP, sendo analisados pela estatística descritiva e apresentados em forma de tabela.

O projeto foi aprovado pelo Comitê de Ética em Pesquisa (CEP) sob o parecer n ${ }^{\circ} 4.018 .759$.

\section{Resultados}

Dos 194 discentes que responderam ao formulário, 50 eram do curso de Enfermagem (25,8\%), 50 de Psicologia (25,8\%), 46 de Nutrição $(23,7 \%)$ e 48 de Fisioterapia (24,7\%), sendo a maior parte com idade entre 20 e 25 anos $(75,3 \%)$ e do sexo feminino com $(77,3 \%)$.

A maior adesão em resposta do formulário ocorreu entre os discentes dos $3^{\circ}, 5^{\circ}, 7^{\circ}$ e $9^{\circ}$ períodos de ambos os cursos. A forma que foi adquirida o conhecimento, podendo marcar mais de uma opção, foi aula teórica 63,4\%; aula prática 54,6\%; curso específico 13, 9\%, chamando a atenção para 30,4\% nunca ter estudado sobre a temática, quanto a descrição de "outros", obteve 9 respostas (4,6\%), sendo apontadas as seguintes formas, "minicurso de SBV e APH”, "estudos individuais", "módulo do curso 
de bombeiro de aeródromo", "treinamento estudando de forma própria por livros", "pesquisas na internet", "no trabalho", "um livro específico", "para uma apresentação específica, sobre cuidados paliativos no formato de Simpósio". Quanto ao tempo da formação ou da última atualização, 34,5\% relatam ter feito a menos de 1 ano; $18 \%$ a mais de 1 ano e 47,4\% nunca participou, conforme a Tabela 1.

Tabela 1- Caracterização sócio demográfica dos participantes do estudo sobre o conhecimento em SBV sobre PCR, Faculdade de Ciências da Saúde do Trairi (FACISA), Santa Cruz-RN, Brasil, 2020.

\begin{tabular}{|c|c|c|c|}
\hline Variáveis & & $\mathbf{N}^{\mathbf{o}}$ & $\%$ \\
\hline \multirow{2}{*}{ Sexo $(n=194)$} & Masculino & 44 & 22,7 \\
\hline & Feminino & 150 & 77,3 \\
\hline \multirow{4}{*}{ Idade } & Menor de 20 anos & 17 & 8,8 \\
\hline & Entre 20 e 25 anos & 146 & 75,3 \\
\hline & Entre 26 e 30 anos & 14 & 7,2 \\
\hline & Maior que 30 anos & 17 & 8,8 \\
\hline \multirow{4}{*}{ Cursos } & Enfermagem & 50 & 25,8 \\
\hline & Fisioterapia & 48 & 24,7 \\
\hline & Psicologia & 50 & 25,8 \\
\hline & Nutrição & 46 & 23,7 \\
\hline \multirow{9}{*}{ Períodos } & $1^{\circ}$ & 15 & 7,7 \\
\hline & $2^{\circ}$ & 7 & 3,6 \\
\hline & $3^{\circ}$ & 33 & 17 \\
\hline & $4^{\circ}$ & 7 & 3,6 \\
\hline & $5^{\circ}$ & 32 & 16,5 \\
\hline & $6^{\circ}$ & 17 & 8,8 \\
\hline & $7^{\circ}$ & 32 & 16,5 \\
\hline & $8^{\circ}$ & 18 & 9,3 \\
\hline & $9^{\circ}$ & 33 & 17 \\
\hline \multirow{5}{*}{$\begin{array}{l}\text { Como adquiriu os conhecimentos } \\
\text { sobre suporte básico de vida? } \\
\text { (Pode marcar mais de uma opção) }\end{array}$} & Aula teórica & 123 & 63,4 \\
\hline & Aula prática & 106 & 54,6 \\
\hline & Curso específico & 27 & 13,9 \\
\hline & $\begin{array}{c}\text { Nunca estudou sobre a } \\
\text { temática }\end{array}$ & 59 & 30,4 \\
\hline & Outros & 9 & 4,6 \\
\hline \multirow{3}{*}{$\begin{array}{l}\text { Além das aulas na graduação você } \\
\text { já participou de outro } \\
\text { treinamento/capacitação sobre } \\
\text { Reanimação Cardiopulmonar } \\
\text { (RCP)? }\end{array}$} & & & \\
\hline & Sim & 39 & 20,1 \\
\hline & Não & 155 & 79,9 \\
\hline \multirow{3}{*}{ Tempo de atualização } & Menos de 1 ano & 67 & 34,5 \\
\hline & Mais de 1 ano & 35 & 18 \\
\hline & Nunca participou & 92 & 47,4 \\
\hline
\end{tabular}

Fonte: Autor.

Na Tabela 2, pôde-se observar as questões que tiveram mais acertos e erros encontradas no estudo. A questão 1 está dentre as que mais obtiveram respostas corretas, com um total de 55,2\%, porém vale ressaltar que, dentre as 194 pessoas, 37 responderam de forma errônea e 50 não souberam responder, correspondendo a $44,8 \%$ do total que não saberiam reconhecer uma PCR se a presenciassem; a questão 2 aborda a cadeia de sobrevivência trazida pela AHA, e apenas 14,1\% acertaram; a questão 3 chama atenção para o número dos que não souberam responder e que responderam de forma incorreta, com $72,2 \%$, aborda um mnemônico e a sequência correta para um atendimento segundo a AHA no SBV para RCP a sequência correta é o $\mathrm{CAB}, \mathrm{C}$ circulação/compressões torácicas, A representa via aérea e B respiração/ventilação.

Na questão 4 houve uma porcentagem de 47,2\%, ficando entre as assertivas que tiveram um maior índice de respostas positivas; na questão 5, observou-se apenas 39,7\% de acertos, essa fala sobre a frequência mínima e máxima respectivamente, temos uma padronização do que é ideal, uma frequência de 100 a 120 compressões por minuto; a questão 6 aborda o local ideal 
para a realização das compressões de alta qualidade e obteve-se apenas 29,4\% de acertos, informação essa, primordial para que se faça uma boa compressão simulando o batimento artificial do coração, chamando a atenção para o percentil que assinalaram a assertiva "comprimir 2 dedos abaixo do processo xifoide", ou seja, na região epigástrica, no estômago, essa atitude poderá levar a alguma lesão de órgão e provável hemorragia interna agravando ainda mais a situação; a questão 7 aborda a profundidade mínima e máxima de uma compressão no adulto, que seria de no mínimo de $5 \mathrm{~cm}$ e no máximo de $6 \mathrm{~cm}$ ou de 2 a 2,4 polegadas, chama atenção para o quantitativo de pessoas que não souberam responder, 49,5\% e apenas 21,1\% acertaram; a questão 8 tratase do conhecimento sobre a Naloxona, uma medicação muito usada como antagonista de opioides, $84 \%$ das pessoas não souberam responder e apenas $10,3 \%$ acertaram.

Um total de 194 participantes, 8 questões referente ao assunto específico, totalizou-se 1.552 respostas, sendo 475 $(30,6 \%)$ assinaladas corretamente, 434 (27,9\%) marcadas de forma incorreta e $643(41,4 \%)$ não souberam responder, conforme a Tabela 2.

Tabela 2 - Distribuição das respostas dos estudantes dos cursos de Enfermagem, Fisioterapia, Nutrição e Psicologia quanto ao conhecimento teórico sobre Suporte Básico de Vida segundo o protocolo da American Heart Association (AHA), Faculdade de Ciências da Saúde do Trairi (FACISA), Santa Cruz-RN, Brasil, 2020.

\begin{tabular}{|c|c|c|c|c|c|c|}
\hline \multirow[t]{2}{*}{ Questão } & \multicolumn{2}{|c|}{ Correto } & \multicolumn{2}{|c|}{ Incorreto } & \multicolumn{2}{|c|}{ Não sabe responder } \\
\hline & $\mathbf{n}$ & $\%$ & $\mathbf{n}$ & $\%$ & $\mathbf{N}$ & $\%$ \\
\hline $\begin{array}{l}\text { 1- Como você identifica uma Parada } \\
\text { Cardiorepiratória (PCR)? Ou seja, quais os } \\
\text { três parâmetros utili-zados para a } \\
\text { identificação da PCR segundo a AHA? }\end{array}$ & 107 & 55,2 & 37 & $19 \%$ & 50 & 25,8 \\
\hline $\begin{array}{l}\text { 2- Qual a sequência correta dos } 05 \text { elos da } \\
\text { cadeia/corrente de sobrevivência em PCR } \\
\text { extra-hospitalar segundo a atualização } \\
2015 \text { da AHA? }\end{array}$ & 27 & 14,1 & 97 & 49,4 & 70 & 36,5 \\
\hline $\begin{array}{l}\text { 3- Assinale a alternativa cor-reta, segundo } \\
\text { diretrizes da aha, } 2010 \text { para RCP quanto a } \\
\text { sequência de procedimentos Suporte } \\
\text { Básico de Vida (SBV). }\end{array}$ & 54 & 27,8 & 76 & 39,2 & 64 & 33 \\
\hline $\begin{array}{l}\text { 4- Qual a relação compressão/ ventilação para } \\
\text { reanimação cardiopulmonar (RCP) no } \\
\text { adulto no SuPorte Básico de Vida (SBV) } \\
\text { (AHA, 2005, 2010, 2015)? }\end{array}$ & 92 & 47,2 & 41 & 21,4 & 61 & 31,4 \\
\hline $\begin{array}{l}\text { 5- Qual a frequência mínima e máxima de } \\
\text { compressões por minuto no suporte básico } \\
\text { ou avançado de vida segundo a American } \\
\text { Heart Association (AHA), 2015? }\end{array}$ & 77 & 39,7 & 37 & 19,1 & 80 & 41,2 \\
\hline $\begin{array}{l}\text { 6- Qual o local das compressões } \\
\text { (posicionamento das mãos) na Reanimação } \\
\text { Cardiopulmonar (RCP)? }\end{array}$ & 57 & 29,4 & 78 & 40,2 & 59 & 30,4 \\
\hline $\begin{array}{l}\text { 7- Qual a profundidade das compressões } \\
\text { torácicas no supor-te básico ou avançado } \\
\text { de vida, mínimo e máximo? }\end{array}$ & 41 & 21,1 & 57 & 29,4 & 96 & 49,5 \\
\hline $\begin{array}{l}\text { 8- Em pacientes com dependência de } \\
\text { opioides conhecida ou suspeita, que não } \\
\text { respondem, apresentam respiração } \\
\text { anormal, mas tem pulso é adequado no } \\
\text { Suporte Básico de Vida (SBV) administrar } \\
\text { qual medicação? }\end{array}$ & 20 & 10,3 & 11 & 5,7 & 163 & 84 \\
\hline Total & 475 & 30,6 & 434 & 27,9 & 643 & 41,5 \\
\hline
\end{tabular}




\section{Discussão}

Os resultados do estudo apontam uma fragilidade no que versa ao conhecimento dos acadêmicos dos cursos da área da saúde acerca da prática de Suporte Básico de Vida. De acordo com o analisado, houve predominância do sexo feminino, com faixa etária entre 20 a 25 anos, com participação equiparada entre os diferentes cursos estudados. Esses dados, portanto, corroboram com estudos que mostram que existe uma maior prevalência das mulheres nas graduações em saúde com essa mesma faixa etária (Freire \& Cavalcante, 2017; Tavares \& Urbano, 2016).

Concernente aos resultados específicos do objetivo do estudo observou-se que a proporção de erros foi consideravelmente superior à de acertos. Houve também uma alta prevalência de estudantes que não sabiam responder à questão específica. Na primeira questão, a maior parte respondeu saber reconhecer uma PCR diante os parâmetros adotados pela AHA.

Pesquisas enfatizam a necessidade de reconhecer uma PCR, pois, a partir do seu reconhecimento, é necessário direcionar as ações que serão executadas, pois após alguns minutos as células dos órgãos nobres, sensíveis à falta de oxigênio, que são o cérebro, o coração e os pulmões, sofrerão com a falta de oxigênio, e as ações minimizam sequelas e pode ter consequência na melhor sobrevida do indivíduo (Riegel \& Tigre, 2012; Tavares \& Urbano, 2016).

Estudo realizado com profissionais de enfermagem mostrou que a maior parte dos entrevistados sabe identificar uma PCR, corroborando com os dados apresentados nessa pesquisa, considerando que os respondentes serão futuros profissionais (Riegel \& Tigre, 2012; Tavares \& Urbano, 2016).

Em relação à sequência correta dos 5 ELOS da cadeia de sobrevivência extra-hospitalar, observou-se que a maior parte não respondeu corretamente ou não soube responder. Esses achados demonstram uma fragilidade na formação em disciplinas de urgência e emergência, devendo considerar que esse componente curricular apesar de ser ofertado na instituição, ocorre de forma eletiva em alguns cursos, e isso, é possível ser associado a um déficit na formação do futuro profissional diante as diversas situações que poderá lidar dentro de sua atuação.

Outra possibilidade para esse déficit pode ser pelo fato de nem todos os discentes terem passados pelo componente curricular que aborda essa temática. Seja por estar no início do curso ou devido o mesmo ofertá-la de forma optativa. Uma pesquisa realizada para avaliar o conhecimento de estudantes apenas de enfermagem sobre SBV mostrou que 60,5\% dos acadêmicos não conheciam a cadeia de sobrevivência das diretrizes de RCP 2015-2020 e a pesquisa realizada em uma Instituição de Ensino Superior (IES) da Região do Nordeste do Brasil mostrou que esse conhecimento menos de 50\% dos internos de enfermagem sabiam. Além disso, o primeiro estudo mostrou ainda que, 85,9\% não sabiam à ordem correta de execução dos procedimentos em uma RCP (Caveião \& Oliveira, 2017; Brandão \& Barros, 2020)

Para essa questão 2, considerou-se o protocolo de 2015 que tinha a composição de 5 ELOS e na atualização de 2020 trouxe a cadeia com 6 ELOS e o leigo pode atuar de forma precisa até o terceiro ELO, assim, o elo 1 é reconhecer e acionar o serviço médico de urgência, 2 realizar as compressões de alta qualidade e o ELO 3, usar o Desfibrilador Externo Automático e apenas 27 pessoas acertaram (Singletary \& Zideman, 2015).

Em relação à compressão/ventilação, observou-se uma alta prevalência de acertos, mostrando o conhecimento adequado dos acadêmicos nesse quesito. Outro estudo, mostrou que (61,6\%) acadêmicos consideram corretos ciclos de 15 massagens e duas ventilações, não corroborando os achados encontrados por essa pesquisa. Para essa relação, até a colocação de uma via aérea avançada, em caso de um ou dois socorristas, é preconizado pela AHA a realização de ciclo de 30 compressões para duas ventilações, caso exista um dispositivo de barreira ((Singletary \& Zideman, 2015; Caveião \& Oliveira, 2017).

Quanto à frequência mínima e máxima de compressões por minuto, houve maior proporção de respostas de não saber, somado também ao feedback das incorretas. Além disso, a maior parte não sabe o local de realização das compressões durante a RCP e nem a profundidade que devem ser feitas durante a compressão. Diferente dos achados encontrados por outro estudo que identificou em sua pesquisa que a maior parte dos discentes respondeu corretamente essas três questões, com quase $70 \%$ 
de acerto em cada. A frequência deve ser de no mínimo de 100 e no máximo 120 compressões por minuto e profundidade de duas polegadas (cerca de $5 \mathrm{~cm}$ ), não ultrapassando de 2,4 polegadas $(6 \mathrm{~cm})$. Para isso, o tórax deve ser comprimido de modo rápido e forte e permita o retorno do tórax entre uma compressão e outra para que a manobra seja eficaz (Aha, 2020; Resende \& Carbogim, 2019).

No que versa ao conhecimento dos acadêmicos quanto a indicação de medicação utilizada, observou-se que houve uma proporção elevada de estudantes que não souberam responder. Dessa forma, destaca-se aqui como limitação do presente trabalho, a ausência da resposta dessa variável por curso e período que poderia apresentar um resultado que refletisse diretamente na área de formação. A AHA no guideline de 2020 já traz com uma maior ênfase dois novos algoritmos para emergência associada à opioides para socorristas leigos e treinados (Aha, 2020).

Ademais, é preciso destacar que parte dos estudantes já teve algum contato com a temática de SBV durante sua formação, seja em sala de aula ou em cursos específicos. No entanto, os protocolos de atendimento passam por constantes transformações de acordo com o avanço da ciência, sendo assim, é preciso que ocorra uma formação clínica-reflexiva desse aluno, de modo que busque conhecimento além das disciplinas da universidade e esteja se atualizando de acordo com novas informações, adquirindo esse hábito durante a graduação e levando para sua futura formação, garantindo ser um profissional atualizado, que trabalha de acordo com a ciência e realiza o melhor atendimento para o seu paciente. Considera-se a valorização da educação continuada e permanente para manter a qualidade dos serviços, além do ensino em saúde (Everett-thomas \& Ruth, 2016; Sbc, 2020; Aha, 2020)

Mesmo com tantas capacitações para leigos existentes, principalmente na era da internet onde se existe um acesso mais facilitado, de acordo com a AHA, uma realidade americana, que menos de 40\% dos adultos recebem RCP iniciadas por leigos, se comparar a realidade brasileira, não se tem estudos, evidências embasando, mas esse dado deverá ser ainda menor. Dessa forma, ressalta-se a importância do domínio do conhecimento, e como estudantes e futuros profissionais, é preciso considerar ainda mais a importância de conhecer sobre o SBV (Aha, 202).

\section{Conclusão}

Evidenciou-se o déficit de conhecimento mínimo sobre SBV para que a vítima tenha suas chances de sobrevida aumentadas. O presente estudo mostrou que precisa uma atenção maior para a temática, pois além de formar profissionais, as universidades transformam e salvam vidas.

Uma limitação do estudo refere-se à ausência da discussão dos resultados por categoria de semestre, assim, não sendo possível averiguar se há diferenças entre alunos ingressantes e alunos que estão saindo da graduação. No entanto, esses resultados serão verificados em uma produção posterior. Contudo, o presente estudo mostrou uma grande carência no conhecimento sobre SBV, cerca de $70 \%$ das pessoas não se mostraram capazes de fazer um primeiro atendimento, sendo este cuidado primordial para o aumento das chances de sobrevida de uma vítima.

Sugere-se novos estudos relacionados à temáticas da área de urgência e emergência em cursos da área da saúde, visando uma melhor formação para o desenvolvimento de competências para atuação profissional.

\section{Referências}

Al-Moahaisen, M. A. (2016). Knowledge and attitues towares basic life support amogn health students at a saudi women's university. Sultan Qaboos Univ Med J. 17(1):e59-e65. 10.18295/squmj.2016.17.01.011

AHA. (2015). American Heart Association. Atualização das diretrizes de RCP e ACE: Destaques da American heart association. https://eccguidelines.heart.org/wp-content/uploads/2015/10/2015-AHA-Guidelines-Highlights-Portuguese.pdf

AHA. (2019). American Heart Association and American Red Cross Focused Update for First Aid: Presyncope. American Heart Association (AHA). https://www.ahajournals.org/doi/epub/10.1161/CIR.0000000000000730 
AHA. (2020). American Heart Association. Destaques das diretrizes de rep e ace de 2020 da american heart association: file:///D:/Meus\%20documentos/Downloads/Hghlghts_2020ECCGuidelines_Portuguese\%20Brazilian\%20(1).pdf

Araújo, L. P., Silva, A. L., Marinelli, N. P., et al. (2012). Conhecimento da equipe de enfermagem sobre o protocolo ressuscitação cardiopulmonar no setor de emergência de um hospital público. Rev. Univap. 18(32): pp66-78. http://revista.univap.br/index.php/ revistaunivap/article/view/106.

Brandão, M. G. S. A., Fontenele, N. A. O., Ximenes, M. A. M., et al. (2020). Autoconfiança, conhecimento e habilidade acerca da ressuscitação cardiopulmonar de internos de enfermagem. Revista cuidarte. 11(2): e982. https://revistacuidarte.udes.edu.co/index.php/cuidarte/article/view/982/1509 http://dx.doi.org/10.15649/cuidarte.982.

Caveião, C., et al. (2017) Conhecimento de acadêmicos de enfermagem acerca das diretrizes de reanimação cardiopulmonar no suporte básico de vida para adultos. Revista Ciência e Saúde On-line. 2(3). https://revistaeletronicafunvic.org/index.php/c14ffd10/article/view/86/81

Departamento de Informática do SUS. 2020. http://datasus.saude.gov.br/

Everett-thomas, R., \& Birnbach, D. J. (2016). An assessment of CPR skills using simulation: Are first responders prepared to save lives?. Nurse Education In

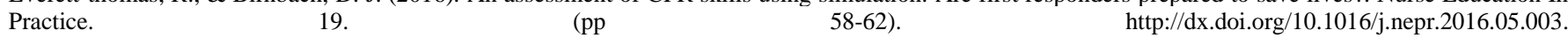
https://www.sciencedirect.com/science/article/abs/pii/S1471595316300233?via\%3Dihub

Filho, C. M. C., Santos, E. S., Silva, R. C. G., et al. (2015). Fatores que comprometem a qualidade da ressuscitação cardiopulmonar em unidades de internação: percepção do enfermeiro. Rev. esc. enferm. USP, São Paulo. 49(6). p. 908-914 10.1590/S0080-623420150000600005.

Freire, I. L. S., et al. (2017). Validation of questionnaire for the evaluation of knowledge of nursing teachers and students on the basic life support. J Nurs UFPE. 11(12):4953-60. https://doi.org/10.5205/1981-8963-v11i12a23556p4953-4960-2017. https://pdfs.semanticscholar.org/d31c/2bc21e920595445b06b2bc10 a067c15b7b88.pdf

Guimarães, H. P, Borges, L. A. A., Assunção, M. S. C., \& Reis, H. J. L. (2016) Manual de medicina de emergência. (1a Ed.): Atheneu.

Partil K. D., Halperin H. R., \& Becker L. B. (2015). Cardiac arrest: ressuscitation and reperfusion. 116(12). 2014-9. 10.1161 / CIRCRESAHA.116.304495

Resende, R. T., et al. (2020) Conhecimento dos acadêmicos de enfermagem sobre suporte básico de vida. Revista de Enfermagem. Recife. 5(13). (pp 12311236). https://periodicos.ufpe.br/revistas/revistaenfermagem/article/viewFile/238984/32187

Riegel, F., Siqueira, D. S., Leopoldino, M. A. A., \& Tigre, A. (2015) Assistência de enfermagem ao paciente com parada cardiorrespiratória: relato de experiência. Rev cuid enfer: Cesuca. 1(1): pp 40-7. http://ojs.cesuca. edu.br/index.php/revistaenfermagem/article/view/862.

Silva, B. T. G., \& Santos, W. N. (2019) The knowledge of health academics with regards to cardiopulmonary resuscitation in basic life support / Conhecimento de acadêmicos da saúde sobre ressuscitação cardiopulmonar no suporte básico de vida. Revista de Pesquisa: Cuidado é Fundamental Online, 11(4). (pp 957961). Universidade Federal do Estado do Rio de Janeiro UNIRIO. http://dx.doi.org/10.9789/2175-5361.2019.v11i4.957-961. https://periodicos.ufpe.br/revistas/revistaenfermagem/article/viewFile/238984/32187

Singletary, E. M., et al. (2015). Guidelines Update for First Aid. Circulation. 132(182) p.574-589. Ovid Technologies (Wolters Kluwer Health). http://dx.doi.org/10.1161/cir.0000000000000269. https://ahajournals.org/doi/pdf/10.1161/CIR.0000000000000269

Sociedade brasileira de cardiologia. 2020. https://www.portal.cardiol.br/

Tavares, A., Pedro, N., \& Urbano, J. (2016). Ausência de formação em suporte básico de vida pelo cidadão: um problema de saúde pública? Qual a idade certa para iniciar? Revista Portuguesa de Saúde Pública. 34(1). 101-104. Elsevier BV. http://dx.doi.org/10.1016/j.rpsp.2015.06.006Acessado. http://www.scielo.mec.pt/pdf/rpsp/v34n1/v34n1a14.pdf 